\title{
INVESTIGATION ON EVOLUTION OF MICROSTRUCTURES AND CHARACTERIZATION DURING FSW OF AZ80A Mg ALLOY
}

\begin{abstract}
Experimental investigation was conducted to find out microstructural characteristic changes arising in the weldments AZ80A $\mathrm{Mg}$ alloys obtained using the friction stir welding. Tools with three different pin profile geometries were employed during this investigation at constant tool rotational speed and feed rate. Tensile tests are performed and the tensile fracture surfaces are examined using the Scanning Electron Microscope (SEM) and the obtained SEM images are used for microstructural investigations. From the experimental results, it was observed that the geometry of the tool pin plays a significant role in producing essential stirring action there by regulating the flow of the plasticized material and leading to the formation of small sized grains having equally distributed fine strengthening precipitates. These structured grains have a direct reflecting impact in increasing the hardness and mechanical properties of the fabricated joints at the nugget zone of the friction stir welded AZ80A Mg alloy joints.
\end{abstract}

Keywords: AZ80A Mg alloy; Friction stir welding; Grain structure; Material flow; Tool pin geometry

\section{Introduction}

Invented, developed \& patented in the year 1991 by The Welding Institute (TWI), Friction Stir Welding (FSW), is an incomparable, attractive, hot shear joining / welding technique comprising a rotating tool which is non consumable in nature [1]. Using FSW, weldments free from defects (including hot cracking, alloy segregation, porosity etc.,) with appreciable \& better mechanical properties and excellent surface finish are obtained in a variety of aluminium, copper, magnesium, titanium alloys, which were previously having some limitations \& constraints during their conventional welding processes [2]. Further, the need for the post welding cleaning of the alloys is completely eliminated when the alloys are welded using FSW. Moreover, an absence of the melting of the base metal provides more benefits to the friction stir welding process compared with other conventional welding techniques [3]. These various attractive and promising characteristic features of FSW make them to be one of the most preferable fabrication processes for joining $\mathrm{Mg}$ alloys.

\section{Literature review}

Friction stir welding parameters (process) inlcuding tool rotation speed, feed rate, axial force, tool material \& tool geometry are found to contribute in a significant manner during FSW especially when joining high melting point and high strength alloys. The quality of the friction stir welded joint was found to be greatly influenced by the process parameters adopted during the welding process [4]. It is observed that limited investigations have been carried out, taking into consideration the impact of the tool geometry during FSW of high strength alloys [5-12]. For example, Blignault et al. [8] made an experimental investigation to understand \& characterize the influences of FSW tool geometry on the weld tensile strength and welding force using completely different instrumented tool geometries. He was able to experimentally and analytically exhibit that the use of a tool geometry having a trifluted tapered pin was able to fabricate sound quality joints with improved mechanical properties. Moreover, they observed numerically derived that these defect free weldments were influenced by the thread pitches of the trifluted tapered tool pin which were about $15 \%$ of plate thickness and $10 \%$ of the pin diameter

Apart from this, majority of the research works and experimental investigations available in the open source literature survey have found to be focused on the impact of the process parameters like feed rate and tool rotational speed during FSW of AZ31B Mg alloy only. Further, the available literatures speaking about the experimental investigations on the microstructural characteristics and changes in Mg alloys during FSW itself are in significant numbers. Hence, in this paper, an attempt has been made to study in detail, the microstructural characteristics and evolution taking place in AZ80A Mg joints fabricated by friction stir welding process at constant tool rotational speed and feed rate using different tool geometry.

\footnotetext{
S.A. ENGINEERING COLLEGE, CHENNAI, INDIA

Corresponding author: drsevvel@saec.ac.in
} 
TABLE 1

Macrostructural observations of dissimilar Mg alloy joints under various FSW process parameters

\begin{tabular}{|c|c|c|c|c|c|c|c|c|}
\hline \hline \multirow{2}{*}{ Alloy } & \multicolumn{8}{|c|}{ Composition wt \% } \\
\cline { 2 - 9 } & Al & Zn & Mn & $\mathbf{C u}$ & $\mathbf{S i}$ & $\mathbf{F e}$ & $\mathbf{~ N i}$ & $\mathbf{M g}$ \\
\hline AZ80A Mg alloy & 7.8 & 0.7 & 0.3 & 0.05 & .10 & .005 & .005 & balance \\
\hline
\end{tabular}

\section{Experimental investigation detail}

\subsection{Composition of base material}

AZ80A magnesium alloy is taken as the base material in this present investigation. The required thickness of $5 \mathrm{~mm}$ of the AZ80A magnesium alloy was obtained by machining the rolled plates to the required dimension. The rolled plates are then machined to required width $\&$ length $(50 \times 150 \mathrm{~mm})$ using power hacksaw followed by the milling process. The chemical compositions of the base metal i.e., AZ80A magnesium alloy are listed in Table 1. This alloy had strength (tensile) of $289 \mathrm{MPa}$, strength (yield) of $191 \mathrm{MPa}$ and percentage of elongation being $8.9 \%$. A square butt configuration $(150 \times 100 \mathrm{~mm})$ was prepared to enable the joining of the AZ80A pieces together by means of friction stir welding technique.

EDS (energy dispersive spectrometric), SEM (scanning electron microscopic) images and optical micrographs of the base metal i.e., AZ80A Mg alloy are illustrated in (Fig. 1a-c) respectively. EDS analysis shows the composition of the base metal and estimates the weight percentage of elements in a quantitative manner (Fig. 1a). Existence of unevenly distributed $\mathrm{Al}_{12} \mathrm{Mg}_{17}$ coarse intermetallic compound structures can be observed along the entire coarse grains from the SEM micrographs (Fig. 1b) of the base metal. Presence of coarse grain structure together with a reasonable amount of sub grains can be seen in the optical microscopic image of the base metal (Fig. 1c).
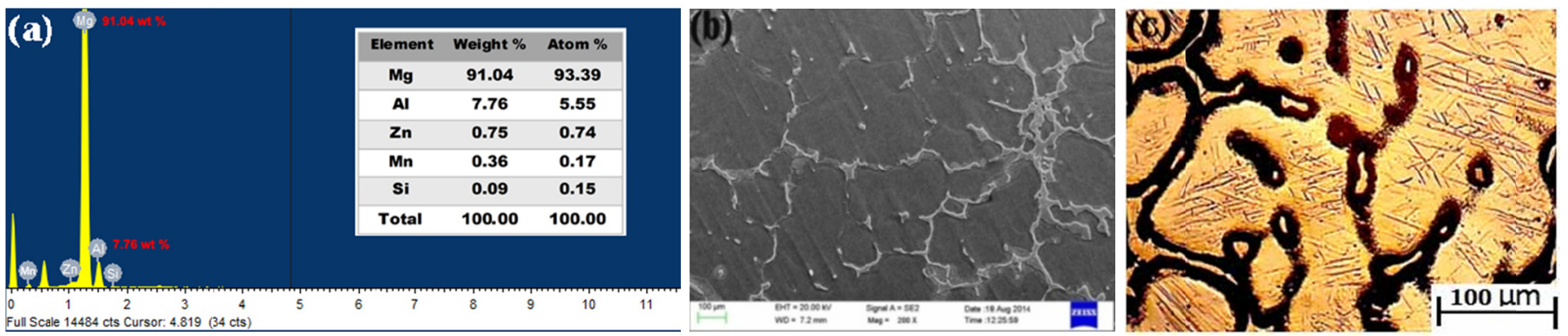

Fig. 1. (a) EDS reports, (b) SEM, (c) Optical micrographs of the AZ80A magnesium alloy (base metal)

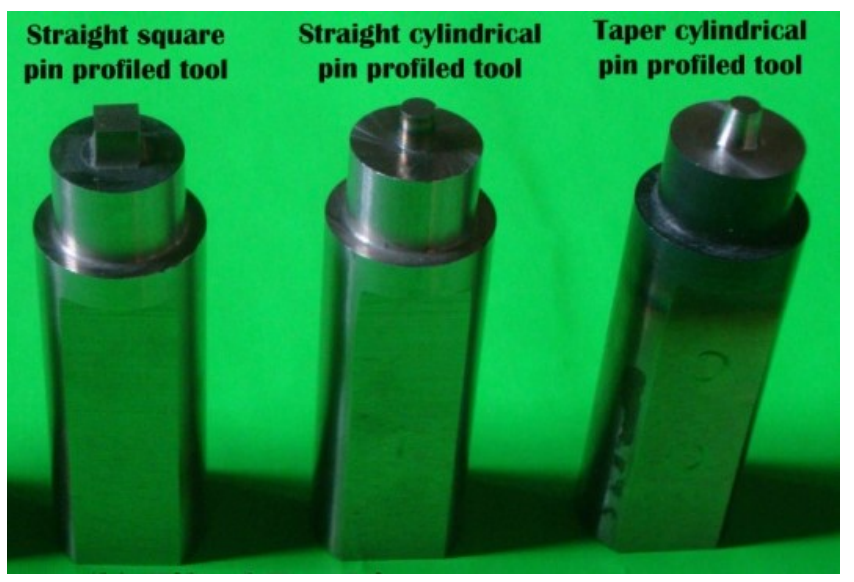

Fig. 2. Photograph of the tools with different pin geomteries employed in this investigation

\subsection{Tool material and geometry}

The tool geometry and design are found to play a significant role in enhancing plastic flow and heat generation. During FSW, the tool pin profile has a major input on material flow and uniformity of the welded joint [13]. The reason for choosing HSS (High Speed Steel) as tool material in this investigation is its high hot hardness, easy processing nature, ease of availability, greater strength, low cost and longer life time [14]. Three different types of tool pin profile geometries namely straight square, straight cylindrical and taper cylindrical are used in this investigation and are shown in Fig. 2.

The specifications and dimensions of the three different tool pin profiles used in this investigation are summarized in Table 2.

TABLE 2

Specifications and dimensions of the tool pin profiles used in this investigation

\begin{tabular}{|c|c|c|c|c|c|c|}
\hline \hline \multirow{2}{*}{$\begin{array}{c}\text { Shape of the tool pin } \\
\text { profile }\end{array}$} & \multicolumn{5}{|c|}{ Tool specifications \& dimensions } \\
\cline { 2 - 7 } & $\begin{array}{c}\text { Outer Shoulder } \\
\text { Diameter, (mm) }\end{array}$ & $\begin{array}{c}\text { Inner Shoulder } \\
\text { Diameter D, (mm) }\end{array}$ & $\begin{array}{c}\text { Pin Length } \\
\text { L, (mm) }\end{array}$ & $\begin{array}{c}\text { Major Pin } \\
\text { Diameter (mm) }\end{array}$ & $\begin{array}{c}\text { Minor Pin } \\
\text { Diameter d, (mm) }\end{array}$ & $\begin{array}{c}\text { D/d ratio of the } \\
\text { tool }\end{array}$ \\
\hline Straight square & 20 & 12 & 4.75 & 4 & 4 & 3 \\
\hline Straight Cylindrical & 20 & 12 & 4.75 & 4 & 4 & 3 \\
\hline Taper Cylindrical & 20 & 12 & 4.75 & 7 & 4 & 3 \\
\hline
\end{tabular}




\subsection{FSW process parameters}

In this investigation, the entire process of friction stir welding was done using the three different tool pin profile geometries under three different axial force conditions $(1 \mathrm{kN}, 2 \mathrm{kN}, 3 \mathrm{kN})$ at constant optimized values of tool rotational speed $(750 \mathrm{rpm})$ and feed rate $(75 \mathrm{~mm} / \mathrm{min})$. Here, the term feed rate indicates the speed at which tool is moving. In total, 9 joints were fabricated using the different combinations of the tool pin profiles, axial force values and other process parameters.

\section{Experimental}

\subsection{Joint appearance}

A part of the joints fabricated successfully during the friction stir welding of the AZ80A magnesium alloys using M35 grade HSS tool with three different pin profiles under various axial force values at constant tool rotational speed and feed rate are displayed in Fig. 3. By analyzing the macrostructures of the joint surfaces fabricated in this investigation, it was observed that the geometry of the tool pin profile has played a significant role in determining the quality of the weld through their influence in the stirring action during the weld, flow of the plasticized material, generation of heat. From the macrostructures, it was found that the defect free sound weld joints were obtained during the use of tool with taper cylindrical pin profile at $3 \mathrm{kN}$ axial force condition.

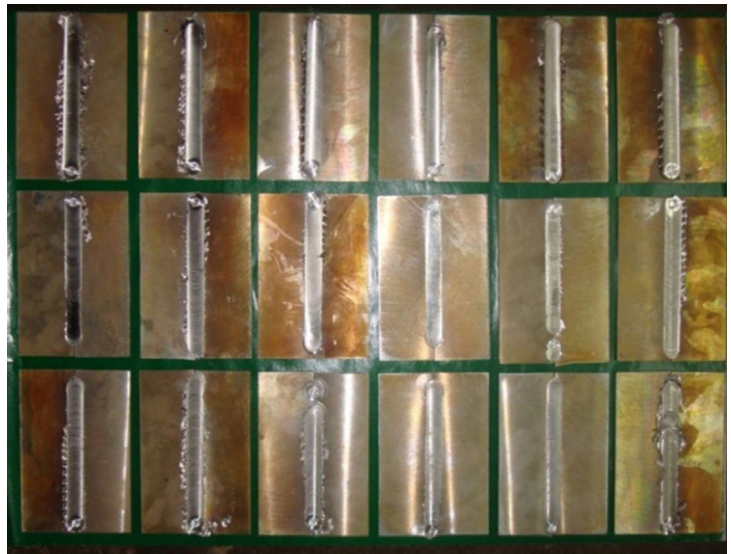

Fig. 3. Photographic illustration of the part of the fabricated AZ80A Mg Alloy specimens by FSW

\subsection{Microstructural Evolution and their Characteristics}

By carefully examining the microstructural images as shown in the Fig. 4, it can be visualized that there is a reasonable amount of difference in the size of the grains present at the nugget weld regions when compared with that of the size of the grains present in the base metal. It can also be noticed that the coarse unevenly distributed grain structure of the base metal have been transformed into an uniformly distributed fine grain structure at the nugget centre region in the fabricated joints. The ASTM: E112-10 methodologies was used to determine the average size of the grains in the centre of the nugget zone of the fabricated joints. The average diameter of the grains present in the base metal are measured to be $29 \mu \mathrm{m}$, but the average diameter of the grains present at the nugget centre zone of the joints fabricated using taper cylindrical pin profile under $3 \mathrm{kN}$ axial force (Joint No. 9) was measured to be only $8 \mu \mathrm{m}$. This measured difference in the grain size reveals us that there are $21 \mu \mathrm{m}$ reductions in the diameter of the grains present at the nugget region. This shows us that the FSW causes refinement of grains during the process and produces joints with finely refined grain structures when compared with that of the base metal. Apart from the various available optical micrographs taken at different regions of the welded joints, the micrographs illustrating the interface of the stir zone (SZ) with the thermo mechanically affected zone (TMAZ) on the advancing side (AS) and retreating side (RS) are shown in Fig. 4.

It can be noticed that during the FSW process, the extrusion of the metal takes place in the AS and this extruded material has been dynamically recrystallized and redeposited on the RS. This extrusion, recrystallization and redeposition process is a characteristic feature of the FSW process. Additionally, this has resulted in the formation of comparatively finer grains on the retreading side of the TMAZ when compared with that of the grains in the TMAZ on the advancing side. From the microstructural images shown in Fig. 4, it can be seen that the grains in the stir zone are uniformly distributed and finer when compared with that of the grains in the TMAZ. Further, the grain size (average diameter) and its distribution in the TMAZ seem to be greatly influenced by the stirring action of the tool pin profile. The joints fabricated with taper cylindrical pin profiled tool employing $3 \mathrm{kN}$ axial force (Joint No. 9) have found to possess grains with relatively fine structure both at the TMAZ and RSTMAZ (Retreating side of the thermo mechanically affected zone) of the fabricated joints compared to those in other joint specimens.

\subsection{Characterization of various FSW zones}

Fig. 5 portrays in detail the microstructural image of the various regions of the defect free sound quality welded joint (Joint No.9) obtained using trinocular metallurgical microscope. From these images, it can be noted that the grain structure exhibiting the presence of large coarse size grains with non uniform distribution have been completed transformed into evenly distributed, comparatively fine sized grains at the nugget zone during the FSW process. These in turn have resulted in the fabrication of sound quality joints which are completely free from defects. The parent metal microstructure of AZ80A Mg alloy with cast microstructure of dendrite network is shown in (Fig. 5a). It can also be seen that the base metal contains cored grains of magnesium solid solution with massive precipitates of $\mathrm{Al}_{12} \mathrm{Mg}_{17}$ precipitates at the grain boundaries. ( Fig. 5b) shows the interface zone at the advancing side. The left side of the picture 
1782
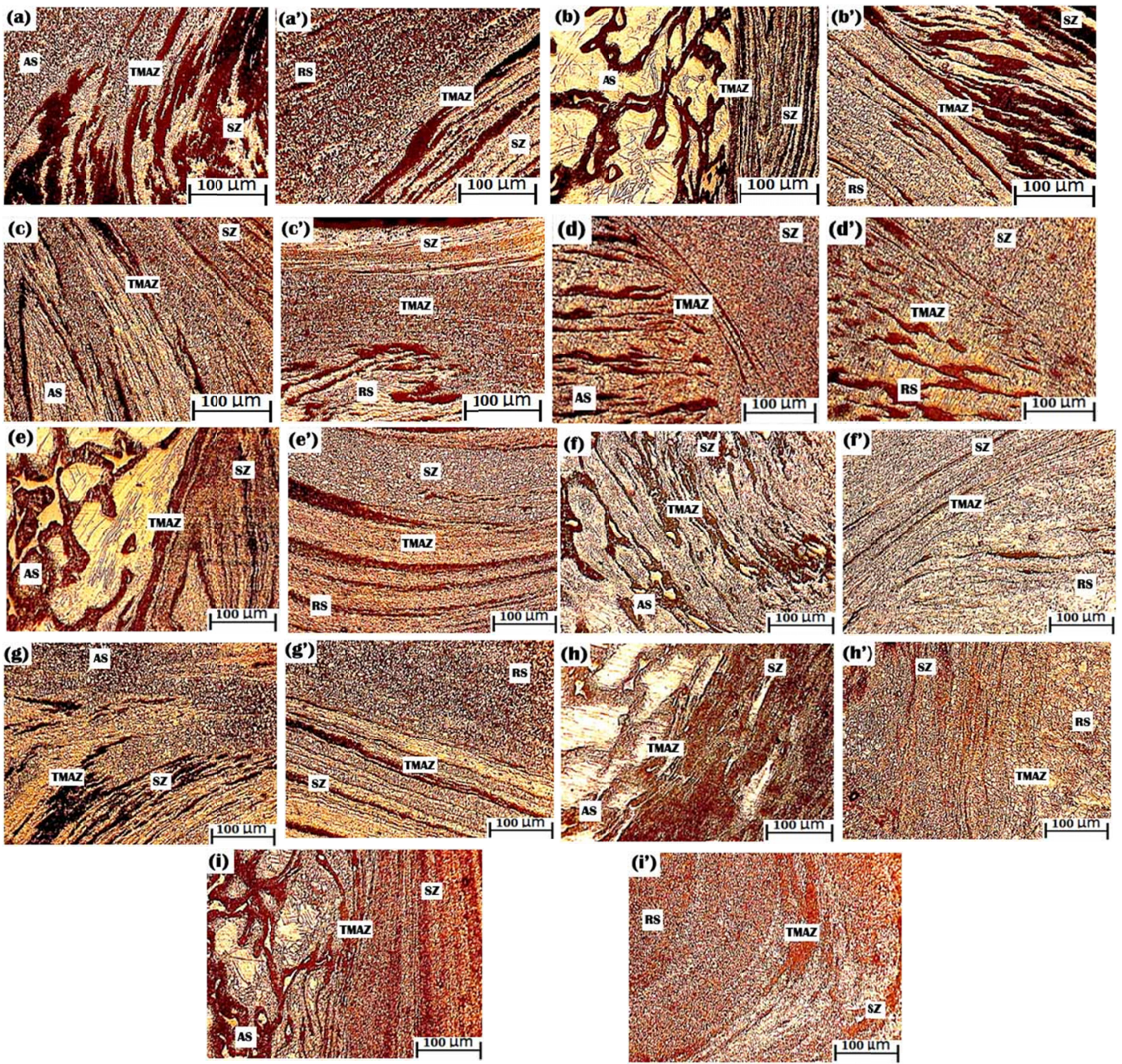

Fig. 4. Microstructural graphs of the interface zone of SZ with TMAZ in AS and RS of the joint specimens with (a \& a') Joint No. 1 (b \& b') Joint No. 2 (c \& c') Joint No. 3 (d \& d') Joint No. 4 (e \& e') Joint No. 5 (f \& f') Joint No. 6 (g \& g') Joint No. 7 (h \& h') Joint No. 8 (i \& i’) Joint No. 9
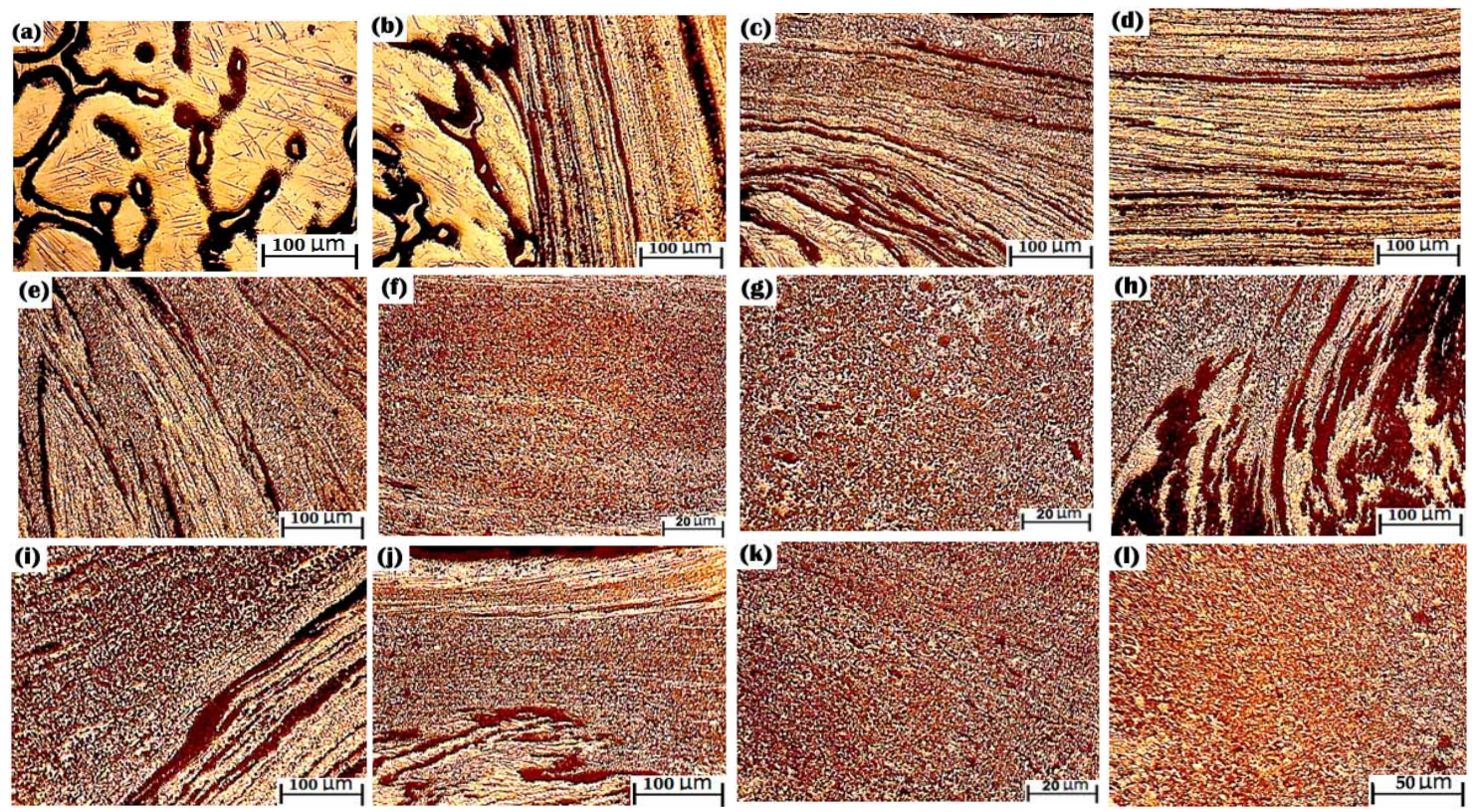

Fig. 5. Optical microstructural images of the defect free joints (Joint No. 9): (a) Base metal (b) Interface zone at AS (c) nugget zone influenced by tool shoulder surface (d) nugget zone (e) TMAZ (f) nugget zone centre (g) nugget zone at higher magnification (h) Interface of TMAZ and SZ (i) Bottom side of TMAZ and SZ interface (j) Interface zone close to RS (k) complete nugget zone at 100× (1) complete nugget zone at 200× 
represents the parent metal microstructure and the right side shows the nugget zone. It can be observed that in this region, the effect of temperature and the stress has lead to good flow of the fusion zone with the fragmented particles which have recrystallized. (Fig. $5 \mathrm{~g}$ ) depicts in detail the nugget zone microstructure along with the grains formed due to super plasticity of metals with dynamic recrystallization. From the optical microstructural images, it can be recorded that the nugget region of the defect free joints are found to possess very fine, homogeneous, equiaxed, unidirectional grains. This is due to the occurrence of the dynamic recrystallization produced by the combined effect of the tool pin profile geometry and axial force values. From these images, it can be noted that the grain structure exhibiting the presence of large coarse size grains with non uniform distribution have been completed transformed into evenly distributed, comparatively fine sized grains at the nugget zone during the FSW process. These in turn have resulted in the fabrication of sound quality joints which are completely free from defects.

\subsection{Fracture Surface Analysis}

The joints produced using taper cylindrical pin profiled tool geometry under a $3 \mathrm{kN}$ axial force value at a tool rotational speed of $750 \mathrm{rpm}$ and feed rate of $50 \mathrm{~mm} / \mathrm{min}$ (Joint No. 9) is observed through SEM and micrographs were obtained for the three different zones of these friction stir welded joints and are illustrated in (Fig. 6a-c). Fig. 6a shows the first interface junction of parent metal and the nugget zone i.e., the heat affected zone (HAZ). In this zone, stirring process had taken place nicely and marginal flow of thermo mechanical transformation of the grains can be seen. The precipitates of $\mathrm{Al}_{12} \mathrm{Mg}_{17}$ seem to be completely dissolved and partly fragmented due to the thermal and stress effects resulting from sufficient amount of heat generation caused by the $3 \mathrm{kN}$ axial force. The microstructure at the nugget zone is portrayed in the (Fig. 6b). It can be noted that due to the high stirring action of the taper cylindrical pin profiled tool, the grains have directed along the rotational axis. The white precipitates of $\mathrm{Al}_{12} \mathrm{Mg}_{17}$ have found to be fragmented and elongated. The matrix magnesium grains have also found to be plastically deformed along the axis of the tool. Fig. 6c shows the thermo mechanical transformation zone with clear flow of grains along with the precipitates of $\mathrm{Al}_{12} \mathrm{Mg}_{17}$ and the grain fragmentation has taken place in a proper manner which has resulted in sufficient plasticity of the material. Moreover, the Energy Dispersive Spectrometry (EDS) results were obtained for the nugget zone and the results are summarized in( Fig. 6e).

From the SEM fractographs in (Fig. 6d), presence of dents and clefts invariably in all the fractured specimens can be seen which reveals us that all the fabricated joints have failed in ductile mode, irrespective of their heat input (axial force value) and tool pin profile geometry used during their FSW process. Yet, small variations can be found in the size and shape of the dents, which has occurred due to the variation prevailing in the nugget zone. The fractograph of the joint fabricated using taper cylindrical pin profiled tool geometry under a $3 \mathrm{kN}$ axial force condition (Joint No. 9) consist of depressions, indicating the occurrence of cup and cone type fracture. This category of fracture pattern takes place only when the material undergoes uniform distribution. The possibility of achieving uniform distribution in the friction stir welded joint is viable only when the nugget zone is free from macroscopic level of defects.

\section{Experimental discussions}

\subsection{Effect of tool geometry}

The fundamental role of the FSW tool pin is to uproar the metal in the plasticized state and to permit movement of this plasticized metal back of it, thereby enabling the fabrication of good quality welds. The geometry of the tool pin plays a very
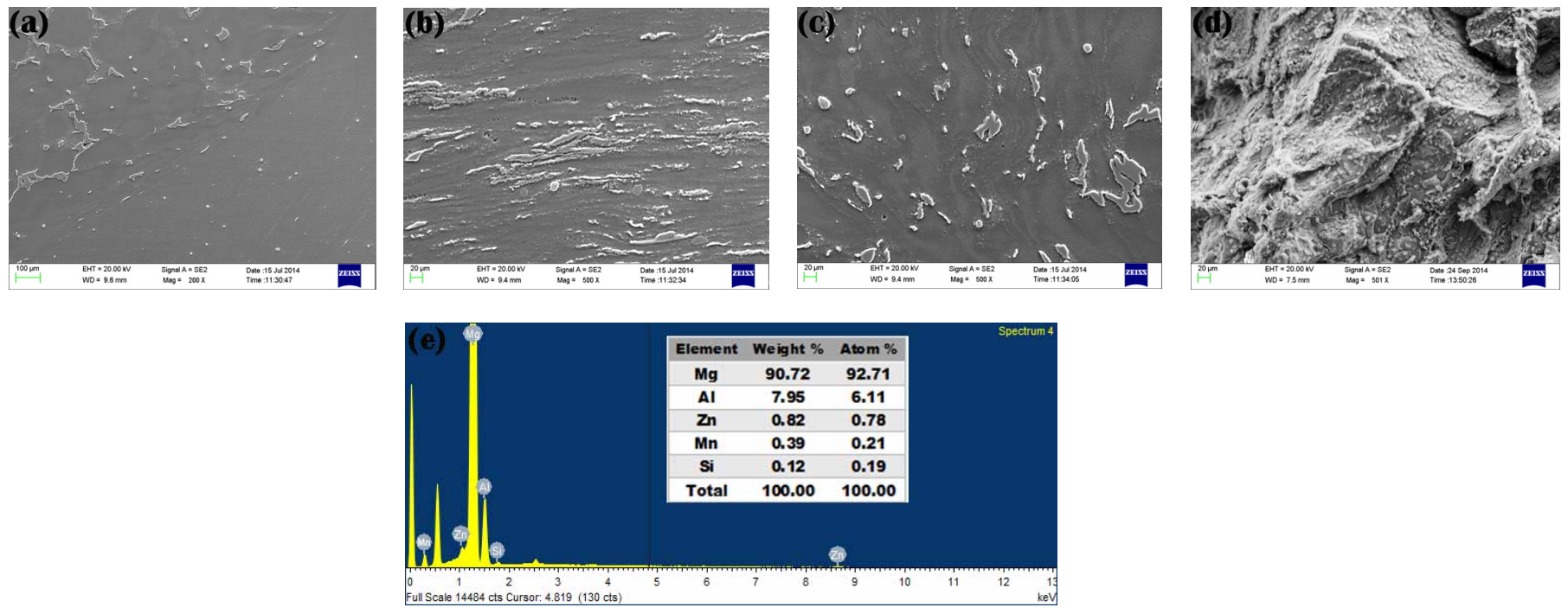

Fig. 6. Photographic illustration of the part of the AZ80A Magnesium Alloy specimens before and after the friction stir welding process under various process parameters using different pin profiled tools 
significant role in facilitating the flow of the plasticized metal, thus helping in regulating the uniformity of the welded joint. The tool pin geometry has a direct impact on the heat generation, plasticity of the metal and the uniformity of the weld [15]. The comparison of the mechanical properties produced using the different combinations of the tool pin geometries and axial force values at constant tool rotational speed and feed rate are graphically illustrated in Fig. 7.

Pin geometries with triangular, tapered profiles are always combined with eccentricity. This eccentricity permits the flow of the impervious plasticized metal around their pin profile surface. Eccentricity of an object during its rotation is directly associated with the dynamic orbit factor arising because of eccentricity. Friction stir welding technique incorporates the concept of dynamic orbit during its process. The link exiting between the dynamic and static volume is found to determine the way for the flow of the plasticized material from the leading edge to the trailing edge of the non consumable rotating tool [16].

This ratio is about 1 for straight cylindrical, 1.01 for threaded cylindrical and 1.45 for tapered cylindrical pin profiles. In addition, the presence of flat tapered surfaces in the tapered cylindrical tool pin profile is found to generate a pulsating stirring action in the flowing material. This pulsating action is absent in the other tool pin profiles. This pulsating action generated in the nugget zone during the use of taper cylindrical tool was multiplied to large numbers by providing sufficient amount of axial force $(3 \mathrm{kN})$, thereby producing finely refined, homogeneous, uniformly distributed small size grains which in turn yielded appreciable mechanical properties and hardness values in joint No. 9 .

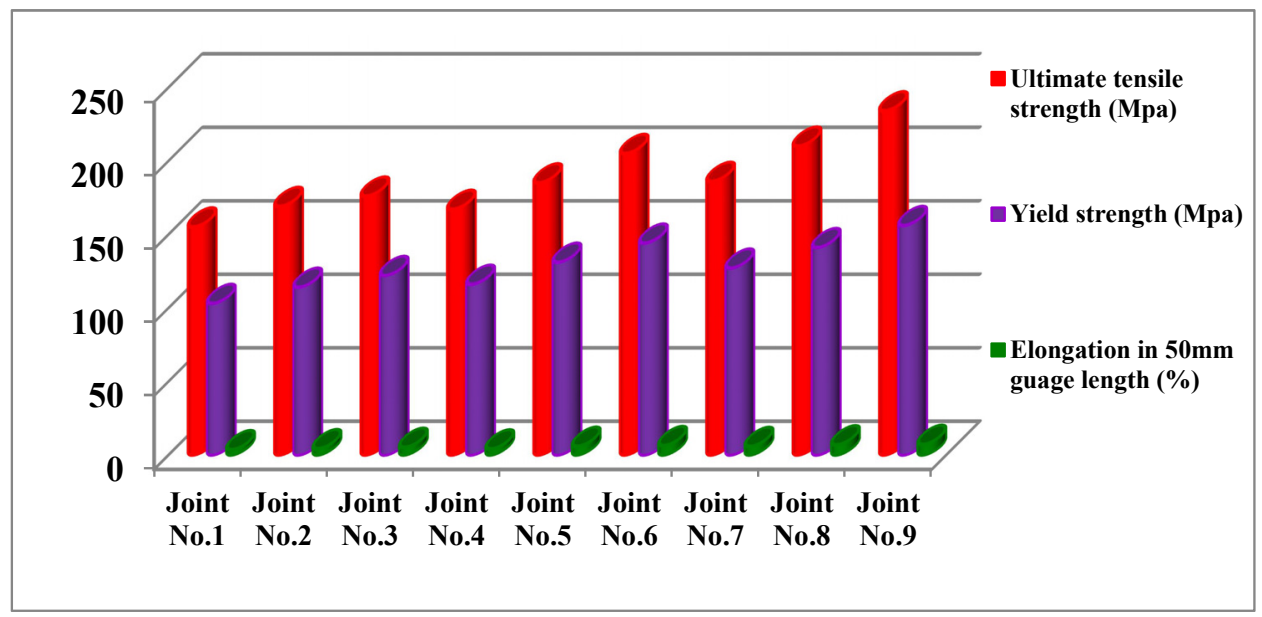

Fig. 7. Comparison of the mechanical properties produced using the different tool pin geometries

\section{Conclusion}

From this experimental investigation, the derived conclusions are mentioned below:

- The geometry of the tool pin plays a significant role in producing essential stirring action there by regulating the flow of the plasticized material and leading to formation of small sized grains having equally distributed fine strengthening precipitates. These structured grains have a direct reflecting impact in increasing the hardness and mechanical properties of the fabricated joints at the nugget zone of the friction stir welded AZ80A Mg alloy joints.

- Tools with three different pin geometries (straight square, straight cylindrical and tapered cylindrical) were used in this investigation. Out of these three different tool pin geometries, tapered cylindrical pin profiled tool exhibited joints with appreciable properties and hardness values when compared with other two tool pin geometries.

The microstructure of these defect free joints is found to possess very fine, homogeneous, equiaxed, unidirectional grains. This is due to the occurrence of the dynamic recrystallization produced by the combined effect of the tapered cylindrical tool pin profile and $3 \mathrm{kN}$ axial force values.
Acknowledgement

The authors gratefully thank the Management and Mechanical Engg Dept., S.A Engineering College, Chennai, India for providing the welding equipment facilities. The authors wish to express thanks to All India Council for Technical Education (AICTE) Govt. of INDIA, funded project (Grant No. 8023/RID/RPS/037/2011-12) for sponsoring FSW machine.

\section{REFERENCES}

[1] X. Cao, M. Jahazi, Effect of tool rotational speed and probe length on lap joint quality of a friction stir welded magnesium alloy, Materials \& Design 32, 1-11 (2011).

[2] P. Sevvel, V. Jaiganesh, Experimental Investigation on the impact of the Tool Material \& geometry in joining of Al 63400 Alloy using Friction Stir Welding Process, Applied Mechanics and Materials 592-594, 312-315 (2014).

[3] V. Jain, R.S. Mishra, A.K. Gupta, Study of $\beta$-precipitates and their effect on the directional yield asymmetry of friction stir processed and aged AZ91C alloy, Material Science and Engineering A 560, 500-509 (2013) 
[4] A. Mohan, W. Yuan, R.S. Mishra, High strain rate superplasticity in friction stir processed ultrafine grained $\mathrm{Mg}-\mathrm{Al}-\mathrm{Zn}$ alloys, Material Science and Engineering A 562, 69-76 (2013).

[5] S. Kumar, G.K.N. Pandey, Application of Taguchi Method for Optimization of Friction Stir Welding Process Parameters to Joining of Al Alloy, Int. J. of Adv. Mat. Manuf. \& Charact. 3 (1), 253-258 (2013).

[6] S. Ugender, A. Kumar, A. Somi Reddy, Microstructure and Mechanical Properties of AZ31B Magnesium Alloy by Friction Stir Welding, Procedia Materials Science 6, 1600-1609 (2014).

[7] P. Sevvel, V. Jaiganesh, Characterization of mechanical properties and microstructural analysis of friction stir welded AZ31B Mg alloy thorough optimized process parameters, Procedia Engineering 97, 741-751 (2014).

[8] D.G. Hattingh, C. Blignault, T.I. van Niekerk,M.N. James, Characterization of the influences of FSW tool geometry on welding forces and weld tensile strength using an instrumented tool, J. of Mat. Proc. Techn. 203 (1-3), 46-57 (2008).

[9] P.Sevvel, V.Jaiganesh, Influence of tool profile during FSW of Mg alloy using optimized parameters, Int. J. of App. Eng. Research 10, 159-164 (2015).

[10] P. Cavaliere, R. Nobile, F. Panella, A. Squillace, Microstructural Behaviour of 2024-7075 Aluminum Alloy Sheets Joined by Friction Stir Welding, Int. J. of Mach. Tools and Manuf. 46, 588-594 (2006).
[11] G.M. Xie, Z.Y. Ma, L. Geng, Effect of microstructural evolution on mechanical properties of friction stir welded ZK60 alloy, Materials Science and Engineering A 486, 49-55 (2008).

[12] R. Zeng, W. Dietzel, R. Zettler, J. Chen, K.U. Kainer, Microstructure evolution and tensile properties of friction-stir-welded AM50 magnesium alloy, Transactions of Nonferrous Metals Society of China 18, S76-S80 (2008).

[13] P. Sevvel, V. Jaiganesh, Effect of Tool Shoulder Diameter to Plate Thickness Ratio on Mechanical Properties and Nugget Zone Characteristics During FSW of Dissimilar Mg Alloys, Transactions of the Indian Institute of Metals 68, S41-S46 (2015)

[14] A.A.M. Silva, E. Arruti, G. Janeiro, E. Aldanondo, P. Alvarez, A. Echecerria, Material flow and mechanical behaviour of dissimilar AA2024-T3 and AA7075-T6 aluminium alloys friction stir welds, Materials \& Design 32, 2021-2027 (2011).

[15] V. Jaiganesh, P. Sevvel, Effect of Process Parameters in the Microstructural Characteristics and Mechanical Properties of AZ80A $\mathrm{Mg}$ Alloy during Friction Stir Welding, Transactions of the Indian Institute of Metals 68, S99-S104 (2015).

[16] P. Sevvel, V. Jaiganesh, Friction stir welding: process parameters, defects \& experimental modeling, International Journal of Applied Engineering Research 10, 518-522 (2015). 